\title{
SPRU
}

Working Paper Series SWPS 2017-15 (August)

\section{User-Intermediaries and the Local Embedding of Low Carbon Technologies}

\author{
Jake Barnes
}

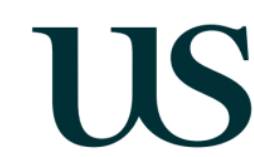




\section{SPRU Working Paper Series (ISSN 2057-6668)}

The SPRU Working Paper Series aims to accelerate the public availability of the research undertaken by SPRU-associated people, and other research that is of considerable interest within SPRU, providing access to early copies of SPRU research.

\section{Editors}

Tommaso Ciarli

Daniele Rotolo

Associate Editors
Karoline Rogge
Paul Nightingale,
Ben Martin, \&
Ohid Yaqub
Tommaso Ciarli
Joe Tidd \&
Carlos Sato
Maria Savona
Andrew Stirling
Caitriona McLeish
Editorial Assistance
Martha Bloom

\section{Contact}

T.Ciarli@sussex.ac.uk

D.Rotolo@sussex.ac.uk

\author{
Area \\ Energy \\ Science, \& Technology Policy \\ Development \\ Technology Innovation Management \\ Economics of Technological Change \\ Transitions \\ Civil Military Interface \\ K.Rogge@sussex.ac.uk \\ P.Nightingale@sussex.ac.uk \\ B.Martin@sussex.ac.uk \\ O.Yaqub@sussex.ac.uk \\ T.Ciarli@sussex.ac.uk \\ J.Tidd@sussex.ac.uk \\ C.E.Y.Sato@sussex.ac.uk \\ M.Savona@sussex.ac.uk \\ A.C.Stirling@sussex.ac.uk \\ C.A.McLeish@sussex.ac.uk
}

\section{Guidelines for authors}

Papers should be submitted to swps@sussex.ac.uk as a PDF or Word file. The first page should include: title, abstract, keywords, and authors' names and affiliations. The paper will be considered for publication by an Associate Editor, who may ask two referees to provide a light review. We aim to send referee reports within three weeks from submission. Authors may be requested to submit a revised version of the paper with a reply to the referees' comments to swps@sussex.ac.uk. The Editors make the final decision on the inclusion of the paper in the series. When submitting, the authors should indicate if the paper has already undergone peer-review (in other series, journals, or books), in which case the Editors may decide to skip the review process. Once the paper is included in the SWPS, the authors maintain the copyright.

\section{Websites}

UoS: www.sussex.ac.uk/spru/research/swps

SSRN: http://www.ssrn.com/link/SPRU-RES.html

IDEAS: ideas.repec.org/s/sru/ssewps.html

Research Gate: www.researchgate.net/journal/2057-6668_SPRU_Working_Paper_Series 


\title{
User-Side Intermediaries and the Local Embedding of Low Carbon Technologies
}

\author{
Jake Barnes $^{\text {ab }}$
}

\begin{abstract}
This article draws on three theoretical fields, innovation intermediaries, socio-technical transitions and domestication studies to develop a process perspective of how user-side intermediary organisations seek to locally embed low carbon technologies. The term local embedding is increasingly used by transition researchers in a variety of ways. The first contribution of this paper is to explore and substantiate the concept of local embedding as the process of integrating technologies into local contexts of use. Intermediary organisations are conceived as contributing to local embedding where they facilitate, configure and broker change towards configurations that work. Nonetheless, understanding how these key intermediary processes relate as well as the influence of system dynamics on the work intermediaries undertake is still largely uncharted territory. The paper's second contribution is a process perspective on the agency of intermediary organisations in local embedding. The resulting perspective offers insights into the agency of user-side intermediaries and later phases of transition processes.
\end{abstract}

Keywords: Intermediary organisations, local embedding, socio-technical transitions, domestication

\section{Introduction}

For many, the international agreement reached in Paris in 2015 marked a turning point in climate governance. For the International Energy Agency, the agreement "boosted momentum for accelerating low carbon technology deployment" but they argued, "more concrete action will need to match ambitions" (IEA, 2016, 2). The International Renewable Energy Agency supported this conclusion, stating, "the technology to push a global renewable energy transformation in next two decades is already here" (IRENA, 2016, 3), albeit again cautioning 'technology is not sufficient' and arguing more innovation was needed at a systemic level to create new business models and supportive policy frameworks and at an operational level to support project delivery and consumer engagement. The Paris agreement and these subsequent statements clearly mark what has been widely acknowledged within policy and practice for some time: many of the technologies required to deliver substantial reductions in emissions over the short to medium term already exist (CCC, 2008; IPCC, 2014).

\footnotetext{
a SPRU - Science Policy Research Unit, University of Sussex, Falmer, Brighton, BN1 9SL, UK

${ }^{b}$ Department of Geography, University of Exeter, Rennes Drive, Exeter, EX4 4RJ

Email: j.j.barnes@exeter.ac.uk
} 
Realising the potential of commercially-developed low carbon technologies is not simply a question of diffusion. Singular technological innovations need to be integrated into existing lifestyles, embedded within new systems of provision at local through to national systems in order for them to have wider, transformational impact (Steward, 2012). How fundamental changes to societal systems of provision occur has been addressed through the study of socio-technical transitions (e.g. Markard et al., 2012; Smith et al., 2010). Research on socio-technical transitions emphasises long-term, multiactor change processes and for the most part has focussed on the development of alternative, increasingly sustainable technological trajectories (Geels et al., 2016; Hekkert and Negro, 2009; Hoogma et al., 2002). This is understandable given how the search for radical solutions was at an early stage of development during the last decade. However, whilst this field has been highly productive, the Paris agreement draws attention to the empirical and theoretical work still required: new technological trajectories have now emerged but there remains important learning around the adaptation of commercially-proven low carbon technologies to diverse local contexts of use (Heiskanen et al., 2015; Späth and Rohracher, 2012). In short, attention has focussed on early phases of transition dynamics. Less attention has been given to what happens beyond the experimentation and development of innovative technologies, specifically how commercially-proven innovations get integrated in diverse contexts of application.

'The integration of technologies into local contexts of use' is defined by Russell and Williams' (2002) as a process of embedding. The term local embedding is increasingly used by transition scholars, but in a variety of ways, to describe and explain how technologies are deployed in diverse contexts of use. For example, Raven et al. $(2008,469)$ claim "sensitivity to local context and the local embeddedness of a project" are key to determining the successful deployment of experimental projects. Schreuer et al. $(2010,741)$ argue "relatively little attention has so far been given to the process of setting up and locally embedding niche [experiments]". Meanwhile, Jalas et al. $(2014,76)$ have explored selfbuilding courses as a stimulus for "local embedding and diffusion of renewable energy technologies". Thus, the term has been used in both an ordinary language sense - to fix an object firmly and deeply into a surrounding mass - and a technical sense, to evoke a concept and, in particular, a process. Consequently, 'local embedding' has characteristics of what Billig (2013) calls a 'semi-technical' term: a term that is neither properly technical (including being clearly defined) nor properly ordinary.

The first contribution of this paper is to substantiate and develop the term local embedding using insights from socio-technical transitions research, domestication studies and research on innovation intermediaries. A focus on local embedding extends attention downstream to the deployment and use of commercially-proven low carbon technologies (innovations). In turn, this places emphasis on the work required to align multiple system elements into contextually contingent configurations that work. In this paper, the topic is approached through the role and agency of intermediary organisations.

The term intermediary has been used to describe a variety of different actors but commonly refers to actors who (1) perform relational work, and (2) operate between other actors and/or artefacts (Moss, 2009). The literature on intermediaries is most developed around innovation intermediaries (Bessant and Rush, 1995; Howells, 2006; Stewart and Hyysalo, 2008). Howells (2006, 720) defines an intermediary as "an organisation or body that acts as an agent or broker in any aspect of the innovation 
process between two or more parties". The role of intermediaries in facilitating transition processes has gained increasing attention since 2009 (Hargreaves et al., 2013; Hodson and Marvin, 2009; Kivimaa, 2014; Lente et al., 2003; Moss, 2009). Early work focussed on the role of 'systemic intermediaries', understood as a new type of organisation operating at a network or system level (Lente et al., 2003) (see also Kivimaa, 2014 and Lukkarinen et al., 2017). Intermediaries have also been studied supporting niche development processes (Geels and Deuten, 2006; Hargreaves et al., 2013) and supporting niche regime interactions (Elzen et al., 2012). More recently Kivimaa et al. (2016) have defined transition intermediaries as those that mediate a sector (such as electricity) or a region (such as a city) towards a systemically new and more sustainable socio-technical configuration.

Common across these studies is a focus on the early stages of innovation processes. In a review of innovation intermediary research Stewart and Hyysalo (2008, 319) suggest, "highly visible supplyside intermediaries..., and the easily identifiable middle-ground agencies ...tend to overshadow the often more informal yet just as crucial intermediaries at the user-end of the supply-use relation". Addressing transition-orientated intermediaries in the governance of energy and water infrastructure, Moss $(2009,1489)$ argues more research is needed into "intermediaries seeking to embed technologies in particular social contexts of application". Meanwhile, Kivimaa et al (2016) have also come to a similar conclusion in a review of intermediaries in transitions, arguing more empirical and theoretical work is required on how intermediary activities contribute to latter phases of transitions. The second contribution of this paper is to help address this gap.

Building on insights from the three literatures above a new process perspective on the agency of userside intermediaries in local embedding is developed. The resulting perspective suggests an idealtypical sequence to key intermediary processes in local embedding and subsequently offers an explanation as to how intermediary activities may contribute to latter phrases of transitions. The perspective also moves beyond existing research by situating key intermediary processes contextually and temporally.

The paper is structured as follows. Section 2 begins by reviewing prior research within the fields of innovation intermediaries and socio-technical transitions for insights into how intermediary organisations contribute to the local embedding of low carbon technologies. To further substantiate and develop the concept of local embedding additional insights from socio-technical transitions and domestication studies are mobilised. Insights from these three literatures are subsequently combined in section 3 to create a process perspective on local embedding via user-side intermediaries. Section 4 then introduces a case study to demonstrate and test the perspective. Section 5 discuss the case's fit and section 6 concludes.

\section{Intermediary organisations and the local embedding of technology}

\subsection{Roles, functions and key processes of intermediaries}

To date much of the work on innovation intermediaries has been concerned with what they do. As a result, several influential typologies have emerged. The most frequently cited are those by Howells 
(2006) and Stewart and Hyysalo (2008). Howells (2006) lists 10 functions of intermediaries within the innovation process but is mainly concerned with intermediation up to commercialisation. In contrast, Stewart and Hyysalo (2008) have identified three key intermediary processes, which, they argue, can be applied to intermediaries working across an innovation's supply and use. In doing so they advance the notion of user-side intermediaries, defined as organisations or individuals "grounded in an institutional, technical and often physical context" that "attempt to configure the users, the context, the technology and the 'content' [of innovations]". User-end intermediaries thus seek to influence users and developers but do not have a final say in how an innovation is used. Stewart and Hyysalo's (2008) first process, facilitating, is conceived as "providing opportunities to others" through the creation of various 'spaces': social (communities, networks), knowledge (skills and know-how) physical (a place or equipment), economic (providing funds) and regulatory (regulations and rules that guide activity and reduce uncertainty). Their second process involves the configuring of technology, projects, users and producers. Configuring thus aligns technologies or projects within local contexts and can be technical but also be symbolic (providing an interpretation of a technology and its use). In their third process, brokering, intermediaries may seek to raise support (financial, human, physical) from other actors such as sponsors and suppliers; intermediaries may attempt to represent end-users and negotiate on their behalf; intermediaries may also broker the entry of other actors into projects or networks and attempt to maintain influence over emerging rules and practices around a technology, project or vision (Stewart and Hyysalo, 2008, 306-308).

Within the study socio-technical transitions similar explorations into the role and functions of intermediaries have occurred. Here, the majority of attention has focussed on intermediary support for the development of alternative niche configurations (Geels and Deuten, 2006; Hargreaves et al., 2013; Kivimaa, 2014). In a review of this literature only four studies were found which engage with later stages of transition processes. Lente et al. (2003) discuss the potential roles of systemic intermediaries across four phases of transition processes (exploration, take off, embedding and stabilisation). They suggest the embedding phase involves creating system 'momentum', building new and deconstructing old (or obsolete) actor networks, alignment system elements, enrolment and learning-by-doing. Within this phase they suggest the following, fairly vague, roles for systemic intermediaries: strategy development, pilot projects, project management, preventing strategic games, analysis and advice. They illustrate their framework with a case study on a Californian Fuel Cell Partnership. Backhaus $(2010,88)$ regards the role of 'independent' intermediaries in energy transitions as "one of bottom-up policy implementers" and describes their role as specialising in the development, implementation and management of programmes. Focussing on the role of users in transitions Schot et al. (2016) argue user intermediaries (that is intermediaries that are also users of the innovation) play an important function scaling up and mainstreaming niche technologies through (1) creating spaces for appropriation and (2) by aligning elements of emerging socio-technical systems. They do not investigate how this work is undertaken. Finally, Hodson and Marvin (2009) don't explicitly talk of transition phases but with a focus on systemic intermediaries working within cities argue they perform two functions. First, intermediaries develop place-based images of technological transitions and play a critical role mediating between these technological possibilities and local contexts. Second, intermediaries position actors and thereby build social networks to pursue local transitions (Hodson and Marvin, 2009). 
Collectively, these typologies and roles provide useful insights into the work intermediaries do and, specifically, their potential to support local embedding processes. In short, intermediaries can take a variety of forms, including individuals and networks as well as public, private or third sector organisations. They contribute to local embedding processes where they facilitate, configure and broker change towards configurations that work. They can be thought of as working between technologies, infrastructures, governance actors, regulations, producers and end-users. They can undertake a variety of roles (e.g. the provision of advice, project management, finance and coordination, demonstrations, lobbying, network-building, knowledge dissemination, training and skills development), they can work over short or long timescales (a few months to years or even a decade) and they can operate on a project basis or take up more systemic coordination and governance roles.

\subsection{The context of intermediaries}

Less developed within research on innovation intermediaries or transition intermediaries specifically, is an understanding of the context in which they operate. Stewart and Hyysalo $(2008,297)$ note two crucial features of the context innovation intermediaries engage with: (1) the "unpredictability of technological change, market organisation and user uptake", and (2) "an absence of existing linkages" between potential end-users and suppliers (Stewart and Hyysalo, 2008, 297). The former reveals important insights about the context of intermediaries and suggests potential dynamics influencing intermediaries working to locally embed technologies. The latter conceptually defines intermediaries through the language of innovation: linkages are required for innovation and embedding to occur.

Backhaus (2010) offers a practical conceptualisation of intermediary activity as taking place within a 'multi-layered' context (Figure 1). Each layer consists of target groups, stakeholders and 'conditions' that may influence an intermediary's project success or failure. The first layer consists of the targeted energy activity, performed by a target group (the second layer) with associated problems and needs. Intermediaries are conceived as targeting the first layer. Other stakeholders and the 'context of the project' (third and fourth layers) are thought to affect intermediary opportunities, enabling or constraining project implementation. Stakeholders include local and regional governments, industry organisations and third sector organisations. Finally, the 'broader context' (the fifth layer) influences all others through conventions, culture and shared social practices but also politics, institutions and market mechanisms (Backhaus, 2010). 


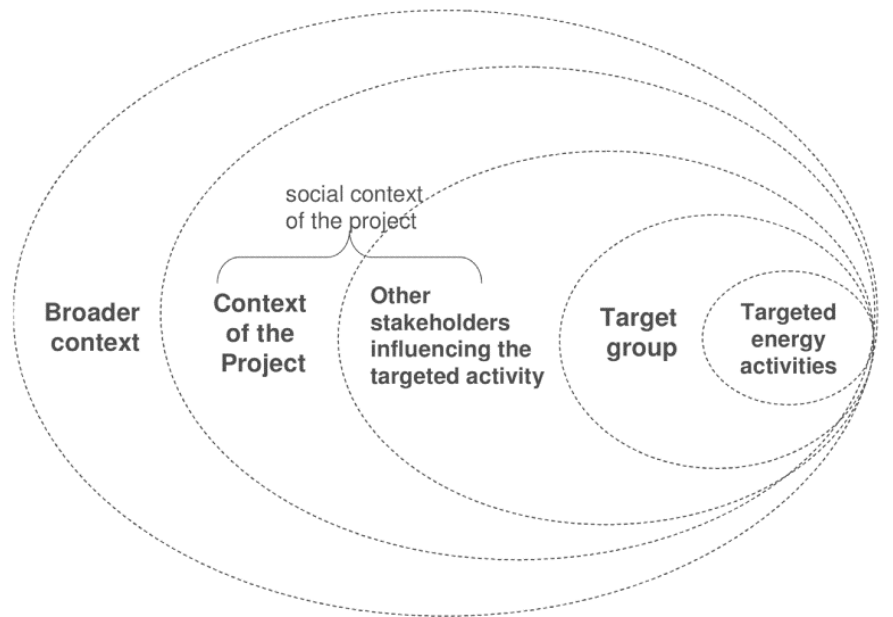

Figure 1: Conceptualisation of intermediary actors' context as multi-layered (Backhaus, 2010)

Backhaus' (2010) conceptualisation begins to unpack the context of intermediary action and in doing so links to the idea of structuration within socio-technical transitions research. A weakness is Backhaus' disregard of time: here, context is static. To further substantiate the concept of local embedding and collect insights for a processual understanding of how user-side intermediaries contribute to local embedding, insights from the fields of socio-technical transitions and domestication studies are useful.

\subsection{Situating local embedding between the social embedding of technology into wider society and the appropriation of technology into households}

Both socio-technical transitions research and domestication studies view innovation and change as a process of co-construction between technology and society. A primary difference is their focus on different scales of analysis.

Research under the umbrella of socio-technical transitions examines how new technologies in emergent socio-technical configurations get embedded in wider society and potentially result in largescale system change. The prominent multilevel perspective (MLP) situates this processes across three interlinked levels: niche, regime and landscape (Geels, 2005). The levels are linked together through structuration (Fuenfschilling and Truffer, 2014; Geels, 2002) but their value, often overlooked, also points towards the 'multi-dimensionality' of socio-technical change processes, including the situatedness of local practices within wider institutionalised structures, with their own particular history, culture and dynamics (Rohracher, 2005). A key insight is that the co-construction of technology and society must be placed within broader contexts of social structures and 'dynamically stable' (Geels, 2005) systems of provision. Thus, to understand the agency of intermediary organisations to locally embed low carbon technologies requires acknowledgement of the stabilising and directing force of increasingly institutionalised regimes and landscapes. Structuration and unfolding change subsequently provide a means to situate intermediary activity at a course-grained level.

The MLP's focus on explaining change from one system to another means it is often critiqued for emphasising the aggregated outcomes of actors (as opposed to the individual agency of actors) (Farla 
et al., 2012; Fischer and Newig, 2016; Shove and Walker, 2007; Smith et al., 2005). It explains innovation processes and sustainability transitions at the macro or societal level and subsequently conceives of embedding as resulting from interactions between firms, policy-makers, consumers, suppliers, civil society, social movements and so forth, each with their own perceptions, motivations, aims and resources (Geels et al., 2008). As Coenen et al. $(2012,971)$ note, the "approach does not fall foul of providing insufficient attention to the societal embeddedness of socio-technical systems" and, as such, can be thought of as explaining the social embedding of technology into wider society.

Agency and local context conditions do, nonetheless, play major explanatory roles in the explanation of historical transitions. These aspects feature prominently within the study of Strategic Niche Management (SNM): SNM focusses on the core processes by which inventions and ideas develop into robust socio-technical configurations, how they grow and then translate into or adapt prevailing regimes (Geels and Raven, 2006; Hoogma et al., 2002; Schot and Geels, 2008; Smith, 2007; Smith and Raven, 2012). As such SNM focusses on radical, socially desirable innovations serving long-term goals (Kemp et al., 1998; Schot and Geels, 2008). Whilst this focus was clearly justified, attention also needs to be directed to later phases of transitions.

Despite a focus on early stage processes SNM provides important insights into local embedding. Raven et al. $(2008,467)$ argues SNM is useful "for analysing the relationship between processes of the local embedding of technologies and the lessons that can be taken from this at the level of emerging niche trajectories". Local embedding, they propose, can be understood as variation (through potential affordances of generic technology to different context specific expectations) and selection (alignment of technological affordances and actor expectations), leading to experimental projects with concrete artefacts. This work is useful for conceptualising local embedding processes as interactions between multiple levels. It also emphasises the importance of projects establishing continuity with existing physical, social and cognitive structures. A weakness is their primary concern with niche accumulation: the paper subsequently has limited understanding of the local embedding process itself and it does not open up for investigation actor strategies or the work required to negotiate expectations (the bottom right corner of figure 2). 


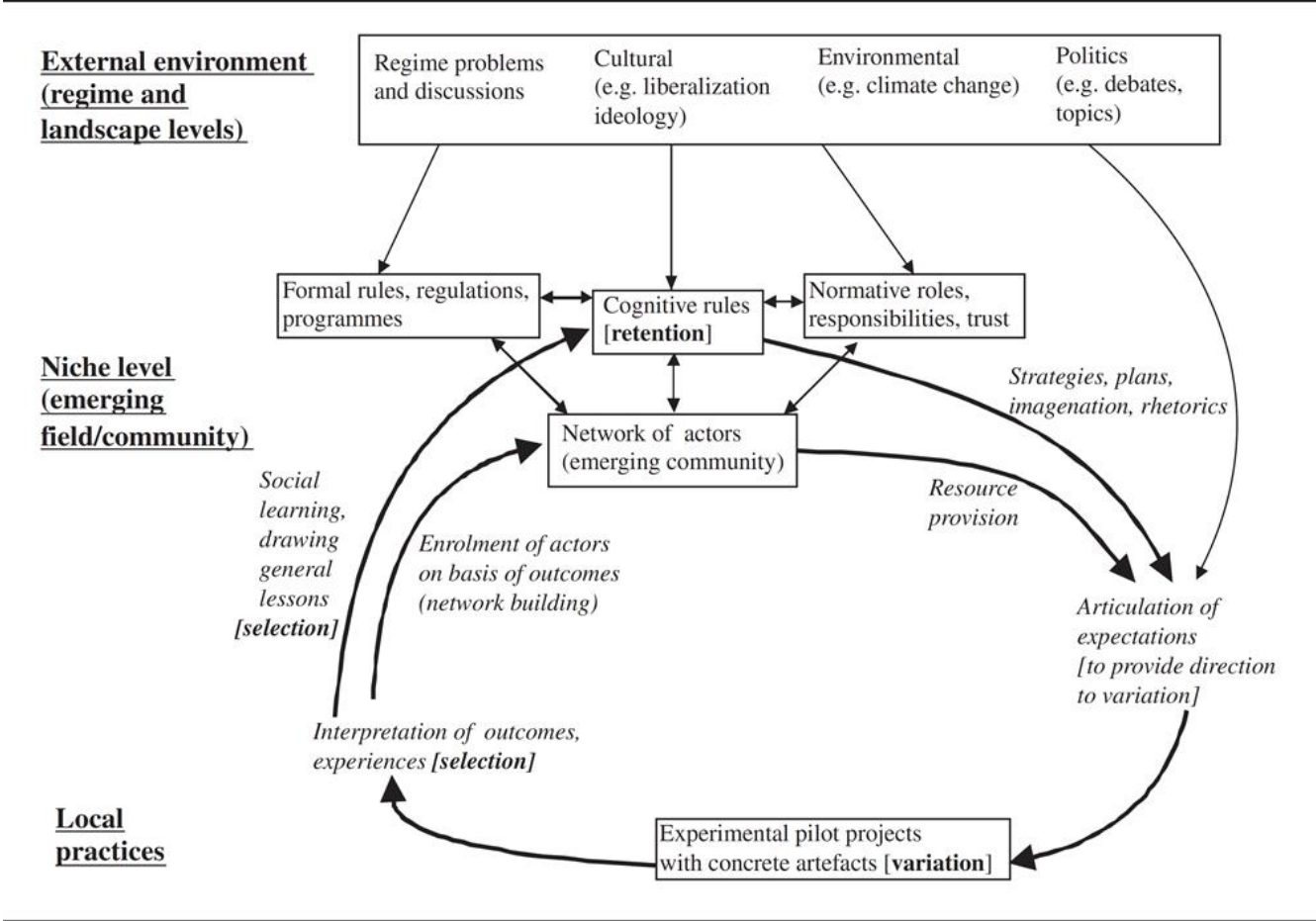

Figure 2: Dynamics in the relation between projects and socio-cognitive technology evolution (Raven et al., 2008)

The more pervasive qualities of the MLP and the focus on early phases of transition processes within SNM can be complemented by insights from domestication studies (Lie and Sorenson, 1996; Silverstone et al., 1992). Domestication studies emphasises the active side of technology use and takes users as its point of departure or primary focus. Domestication is conceived as a multidimensional process where the technology must be: acquired, (brought or made accessible in some way); placed (physically and mentally); interpreted (given meaning and giving symbolic value) and; integrated within social practices (Sorenson et al., 2000). Strategies of domestication are thought to involve practical work (users need to develop patterns of use around technologies), symbolic work (through giving meaning to technologies), and cognitive work in order to learn about technologies (Lie and Sorenson, 1996).

Early domestication research was principally concerned about making the technology 'one's own' and concentrated on 'the moral economies of the household' (Silverstone et al., 1992). Nonetheless, the approach has also been applied in wider contexts and at larger scales, such as cities and regions (Berker, 2011; Lægran, 2005; Lamvik, 1996; Sorenson, 1996). Key individuals or 'local experts' (Stewart, 2007) are also thought to provide support to domestication processes - such as interpreting new technologies and providing information and ongoing support.

One of the most important insights is that new technologies do not simply diffuse but must be integrated within user practices, negotiated in local rules and socially and culturally adopted. The approach is useful for backgrounding technological development to focus solely on the use of marketready technologies in local contexts of use. However, moving beyond the household as the unit of analysis has resulted in a challenging and weakening of the conceptual frame (Haddon, 2011). One promising means to overcome this issue is to draw on the idea of structuration and multiple context 
layers from the MLP. Domestication studies also highlights questions not addressed by broaderbrushed evolutionary approaches, such as the MLP and SNM: it asks about the detailed processes involved in the co-construction of technology and society, it introduces a stronger role for agency in the creation of socio-technical systems and creates space for contingency and alternatives.

Building upon the above the discussion local embedding can be conceived as occurring in relation to a local context, a region, city or community. As a process, it is defined by the integration of technologies into local contexts of use. This entails the alignment of multiple system elements within emerging socio-technical configurations, which thereby creates openings for different actors to make moves and interact. In the renewable energy sector for instance, governmental bodies, firms, social enterprises and end-users are all involved in one or more element of embedding. At the local scale, the number of actors may be reduced to those who make moves or interact with the technology within a relatively bounded socio-technical system. The 'local' of local embedding thus emphasises both the geographical situated-ness of the embedded technology and the local alignment of technologies, actors and institutions around new socio-technical configurations. Different aspects of local embedding are apparent. From the material installation of technologies, through creating market arrangements and industry structures (with knowledge and knowhow), to societal awareness, understanding and acceptance of the purpose and use of technologies. Local embedding thus has material, social, cognitive and institutional components which co-evolve over time. In this sense, local embedding can also be viewed as a long-term process with no definitive end: whilst singular innovations can be appropriated, knowledge and knowhow, local market processes and policies and so forth continue to evolve. In short, local embedding is a contextually and temporally contingent process: broader context dynamics (made up of multiple system elements such as national policy and industry structures) evolve whilst local policy and culture also develop, changing the opportunities for local embedding.

\section{Analytical framework: local embedding by user-side intermediaries}

To develop a processual understanding of local embedding via user-side intermediaries' insights from the above literatures are combined using an appreciative approach (Geels, 2002; Nelson and Winter, 1982).

Stewart and Hyysalo's (2008) three key intermediary processes provide a foundation. To situate these processes contextually and temporally two additional elements are introduced. First, intermediary activity is initiated by an identified opportunity. Actions are rarely arbitrary but are undertaken with intent following the identification of a perceived opportunity. Second, intermediary activity produces outcomes, whether intended or unintended or of major or minor significance. With these two additions, an ideal-typical sequence to user-side intermediation for local embedding is proposed (figure 3):

1. From a basic set of aims intermediaries draw upon their knowledge and experience to identify opportunities. They interpret and contextually situate national policies and market dynamics within their local system. Their experience of and connection to end-users further inform the identification of opportunities.

2. From an identified opportunity a project is configured (Stewart and Hyysalo, 2008). 
Configuring involves interpreting the technology and its use within the local system, the development of place-based images of potential socio-technological futures and the configuring of users and stakeholders (Hodson and Marvin, 2009). Technologies have to be assembled in particular configurations within the local context: such configuration is technical but also symbolic (providing an interpretation of the technology and its use), social and institutional (creating new ownership and management structures) (Stewart and Hyysalo, 2008). Such configurational activity may also build social networks behind particular configurations of technology and use.

3. Having designed a project, intermediaries seek to broker support from various local and external stakeholders as well as their target audience. Brokering is important for a variety of reasons. In the early stages of local embedding, technological visions are explored with local stakeholders and expectations are developed (Raven et al., 2008). Intermediaries may broker the entry of local actors into their place-based technological vision (Hodson and Marvin, 2009), increasing credibility and access to resources. Brokering negotiates resources (financial, social, technical, physical etc.) with which to undertake projects. However, brokering is not one-way. Interactions with stakeholders may reveal alternative interpretations of the technology, local contexts and visions and may reveal competing ideas about the appropriate form of projects. Brokering, therefore, is likely to result in alterations to the design and aim of projects (the intermediary's configurational activity). It is in this sense that brokering can often result in the $r e$-configuring of projects because intermediaries have to be responsive to others (Stewart and Hyysalo, 2008).

4. Following a period of configuring and brokering, intermediaries undertake their projects and in doing so begin creating a variety of facilitation spaces (Stewart and Hyysalo, 2008). Examples might include events, awareness raising campaigns, workshops, demonstration projects and so on. Each 'space' requiring some degree of prior configuring and brokering by the intermediary.

5. Finally, facilitation activity results in outcomes on local embedding, such as increasing user knowledge or awareness and ultimately creating new socio-technical configurations.

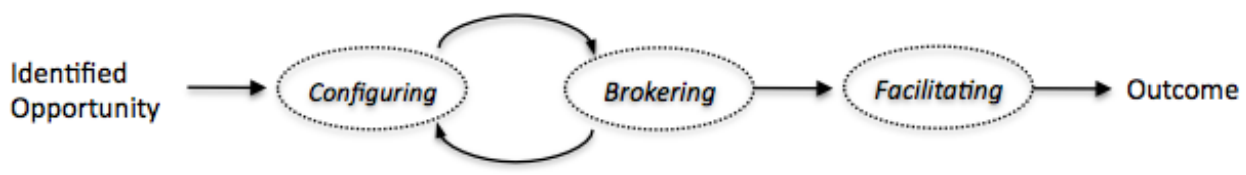

Figure 3: an ideal-typical sequence to key user-side intermediary processes in local embedding

This sequence can be characterised as ideal-typical because (1) each step accentuates a distinct intermediary process, (2) it situates key intermediary processes according to what necessarily comes before, and (3) it encompasses what might be expected in a theoretical case. This sequence adapts and extends Stewart and Hyysalo's (2008) framework by situating key intermediary processes over time. Yet it still leaves unclear how intermediation is situated contextually. To situate user-side intermediary activity insights from Raven et al (2008) and Backhaus (2010) are used.

Three context layers can be usefully distinguished. First, the local socio-technical system constitutes the primary focus of analysis and is particular to the local geography, natural resources, local 
governance structures and actor networks. Due to existing social, economic, political and ecological relations each system is endowed with different resources and capacity to locally embed technologies (Hodson and Marvin, 2009). It encompasses other stakeholders (such as local governments, local industry, housing associations, social groups and social movements) as well as target end-users. Second, communities of end-users sit nested within the local system. End-users are neither static nor homogenous and have multiple ways of thinking and acting (Backhaus, 2010). Through their energy activities and daily practices, end-users can change tangible elements of the local system. The local system is in turn situated within larger system aggregations and influenced by broader social, economic and institutional structures which constitute the third layer or 'external environment' (following Raven et al., 2008). This level includes regime problems and discussions, culture and politics and debate, which exert influence on all other layers through formal, cognitive and normative rules. National government policies and regulations alongside market institutions exert influence (Raven et al., 2008) whilst broader dynamics of technological change and user uptake are expected to influence local contexts of action (Stewart and Hyysalo, 2008). Together these layers function as an affordance, enabling and constraining the local embedding of technologies by intermediaries (figure 4).

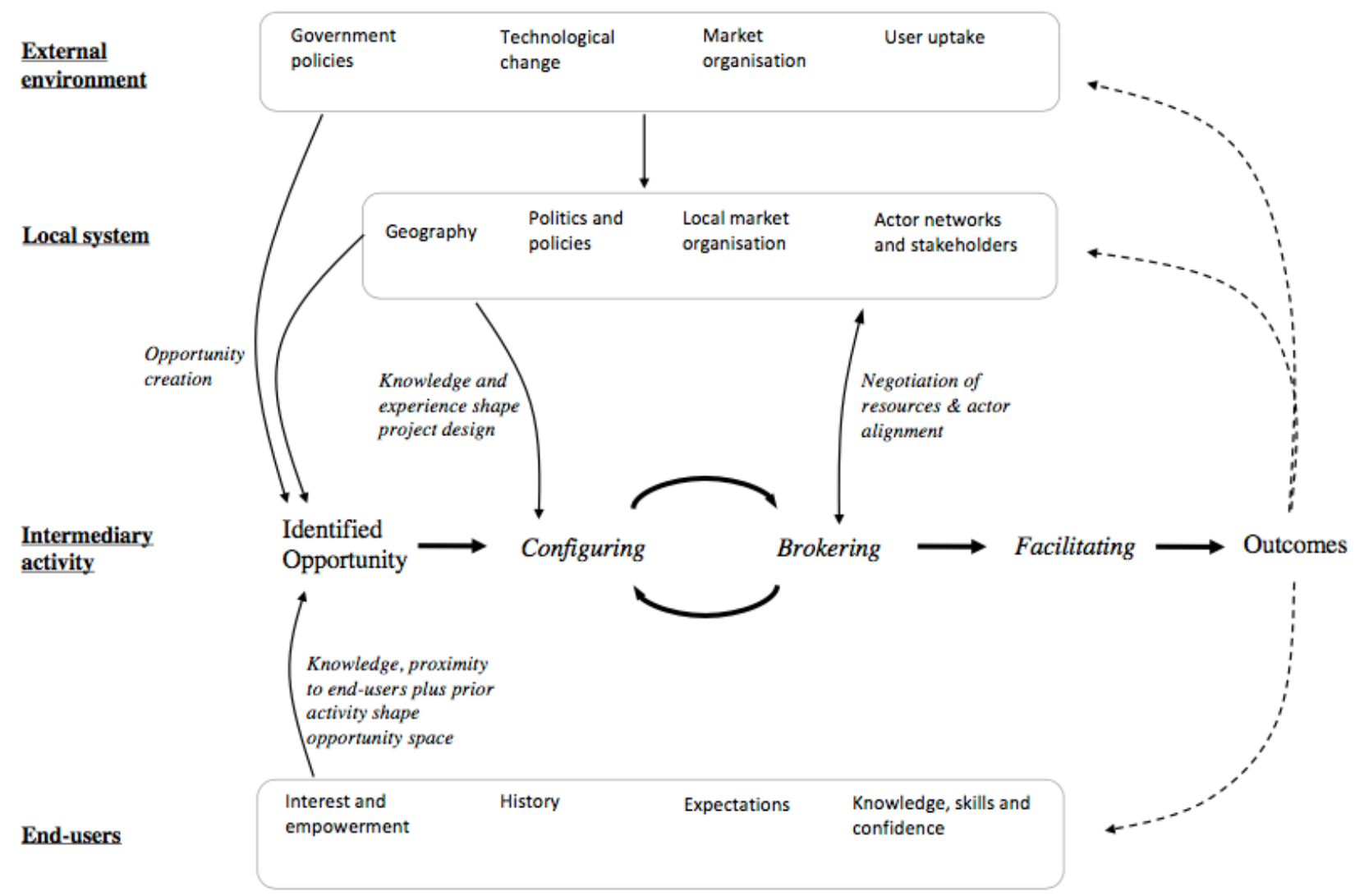

Figure 4: Dynamics in the relation between context and the local embedding of technology via user-side intermediaries

The following section provides an historical narrative of an intermediary's attempt to locally embed solid-wall insulation. The case study was built up through (1) a series of semi-structured interviews with intermediary actors, project partners and citywide actors, (2) document analysis, both internal to the project and relevant external documents from the local system and external environment, and (3) participant observation. The aim here, is not to uncover new material but illustrate the perspective. The 
following case study utilises a narrative approach (Pentland, 1999; Pettigrew, 1997) combined with visual mapping (Langley, 1999) to first introduce the case and second test the case against the analytical framework.

\section{A user-side intermediary's engagement with solid-wall insulation}

Solid-wall insulation (SWI) covers a variety of technologies that reduce heat loss through walls of a solid construction, a building technique prevalent in the UK up to the 1930's ${ }^{1}$. In 2014 seven million solid-walled houses were estimated to be in need of insulation in the UK (CCC, 2014). The UK market for SWI is 'embryonic' (DECC, 2012). Current challenges include reducing the cost of installation, creating user awareness and demand for the technology, supporting the formation of new installation contractors and streamlining the planning process. Further installation challenges include overcoming weather-related delays and effective project management. There is a growing consensus that SWI will require area-based, local action to develop necessary linkages between system elements (Banks and White, 2012; Boardman, 2008; CCC, 2012; DECC, 2013; Mallaburn and Eyre, 2013).

The following case study traces a community interest company (Bristol Green Doors (BGDs)) as it undertook a SWI demonstration project. The project ran between December 2011 and August 2012 and installed SWI to the back and side elevations of a terrace of six properties. BGDs had been formed a year earlier to promote the retrofitting of local households in Bristol, southwest England. The demonstration project ran alongside existing activity, the holding of eco-open home events in which householders who have installed retrofit measures open their doors to the public to share their experience.

\subsection{The identified opportunity}

In December 2011, the UK Department for Energy and Climate Change (DECC) announced short term funding to support: (1) energy efficiency activities - such as household energy surveys (to gather information), engagement events (to stimulate user interest) and the installation of demonstration technologies and measures such as SWI - and (2) renewable energy activities. Applications had to be submitted within two or six weeks.

To BGDs the funding presented an opportunity to demonstrate SWI to local residents, to trial multiproperty installations and engage the local population through a further eco-open home event. A variety of reasons underpinned their logic. They considered SWI an important technology in a city where terraced, solid-walled housing comprised $36 \%$ of properties. A material demonstration was also thought useful to engage local residents, communities, local industry (specifically building trades), local and national policy-makers and strategic partners. BGDs recognised the limited number of SWI certified installers within the city, were aware of the need to generate user interest in the technology and the potential to reduce costs through multi-property installations. They were also aware that prior national deployment rates had been low, reliant on large national contractors and primarily undertaken

\footnotetext{
${ }^{1}$ SWI can be undertaken internally resulting in reduced living space or externally requiring planning permission and potentially altering the appearance of the property. Hybrid systems combine both internal and external insulation.
} 
on social housing. A demonstration project, they believed, had the potential to raise interest in the technology and prepare the city for the planned launch of the Green Deal (a new national government policy) in 2013.

In identifying this opportunity, BGDs drew on knowledge of the local system (e.g. material characteristics of the city) and the external environment (e.g. government policy and ambitions, prior national deployment). They drew on their experience of holding eco-open home events and ideas about what was required to support the further deployment of the technology (e.g. local industry formation).

\subsection{Designing a SWI demonstration project: configuring and brokering the project}

From the opportunity presented BGDs concluded a SWI demonstration project fitted the funding criteria and their ambition to support the local retrofitting of Bristol homes. Their subsequent application aimed to 'promote and normalise low carbon retrofitting on 'hard-to-treat' private sector homes and capture key learning points for communities and businesses for the successful delivery of multi-property installations'. They sought to achieve this by: (1) installing external SWI to the back and side elevations of six hard-to-treat properties, (2) engaging 300 members of the public in the project during an open-home event, and (3) engaging community groups, local authorities, local businesses and professional bodies in multi-property SWI installations and how to deliver them. SWI was not proposed for the front of the terrace because conservation requirements required internal insulation to be used and this meant increased disruption to householders.

For BGDs the form and extent of the project coalesced quickly. But to submit a funding application BGDs also had secure agreement from the householders at their chosen site and obtain at least three building contractor quotes. The site, a terrace comprised of three owner-occupied households and a fourth house converted into three rented flats, was selected because of knowledge of residents (and their previous interest in SWI). To obtain contractor quotes quickly, BGDs drew up a building specification including basic measurements and site photos. It stipulated a form of external SWI to the sides and rear walls of the terrace to bring them up to current building regulation standards.

Within two weeks of the funding being announced an application was submitted. It included three quotations from local contractors but not whom would be used. Instead BGDs argued it wasn't a choice they could make because the final decision needed to involve terrace residents and the landlord who would be contributing $20 \%$ to the cost of the works. Letters of support were also gathered from local stakeholders and national actors. On the 16th January 2012 BGDs was awarded funding: they had until the end of March to complete the project (two and a half months).

In this short period (totalling 6 weeks), BGDs configured the technology and project in the local context and brokered financial support. The design of the project was influenced by the funding they sought, the existing material characteristics of the terrace and resident expectations. Combined with ideas about what the project should achieve (e.g. engage multiple actors), BGDs interpreted the technology and its use within the local system.

\subsection{Negotiating the project with householders and local planning rules}

Have secured funding but before the project could begin agreement from householders first had to be 
sought. Local planning rules also had to be negotiated. On the 19th of January 2012 the project plan, financing, expectations of their involvement and next steps were discussed with terrace residents. Contracts were sent out a few days later. A contractor (who agreed to the award payment schedule) was then chosen. For householders, one contentious issue was extensions to existing window sills. The Victorian terrace included Bath Stone windowsills and quoins ${ }^{2}$ at the front and some concrete replacement sills. Householders were keen to retain these features and character. As a compromise the contractor suggested using concrete extensions using steel Reid bars. The approach - described as 'technically not the best solution' - held the potential for cold bridging and water penetration. The alternative, to remove the windows, add new sills and replace the windows, required additional time and disruption, plus rising costs. Concrete windowsill extensions were agreed as a compromise solution between contractor, residents and BGDs.

Second, local planning regulations had to be negotiated. The terrace was not in a conservation area nor were the houses listed. Despite this, planning permission was required on the side elevations. An application was submitted on 30th January. A positive decision was made on the 9th March two weeks earlier than expected and was helped through by supportive local councillors making 'judgment calls' about the project's limited visual impacts and its compliance with local sustainability criteria.

Each of these instances presented further configuring and brokering of the project. First against householders and then local planning rules. Each instance provided further detail to the form and shape of the project. They did not, as such alter the broader design of the project (how it was configured) nor its financial basis (how it was brokered), which came before.

\subsection{Installation and engagement}

In mid-February and whilst planning consent for the side elevations was secured, work commenced on the rear elevation. Scaffolding was erected and supporting works undertaken: replacing eaves, extending wall fixtures and boiler flues and installing windowsill extensions. Then in late February a period of cold weather threatened to delay the project: the glue used to bond the insulation boards to wall would not set below 5C. Worried about potential delays, BGDs contacted the fund administrator: their response stated they would not penalise the project due to weather-related delays. The email was kept on file for future reference.

From February onwards, multiple engagement events were undertaken to community groups and local building trades. Regular newsletters and a project blog communicated progress and lessons about the project as it got underway. A local newspaper covered the start of the project and promoted the ecoopen home event. Then, over the weekend of 17-18th March 40 homes, supported by 58 event stewards (all volunteers), opened their doors to the public receiving nearly 1850 visits in total. At the terrace two households were open, receiving approximately 150 visitors over two days, including the local MP. Of those attending 50\% cited wanting to learn more about SWI as their primary reason for visiting, $96 \%$ stated a good or excellent understanding of the technology following their visit and 50\% stated they were likely to do something to make their home warmer as a result ${ }^{3}$. In addition, 2,700 people

\footnotetext{
${ }^{2}$ Quoins are masonry blocks at the corner of a wall.

3 BGDs' own event evaluation.
} 
visited the demonstration project website in the run up to the event. The following week the terrace was visited by the fund administrator and resulted in two national case studies. Two further events were held with local and regional buildings trades in mid-April and then late June. A second event to local community organisations in May communicated progress and lessons about the terrace and broader lessons were shared with DECC at a meeting in early May.

Back at the terrace, the 31st March completion deadline quickly passed: all insulation board had been applied but the topcoat of render remained. Between April and July, the installation slowed down. Prolonged wet weather posed problems for the application of render: it was likely to run off the walls. In contrast, hot weather meant the render was likely to crack from setting too quickly. The installation was completed in mid-August. Post installation surveys were undertaken and revealed modest improvements in their energy performance. Two further case studies were produced by national intermediaries to disseminate lessons. Two videos followed, receiving 700 and 900 views respectively over the following two years.

This final period is dominated by facilitation processes. The installation of SWI at the terrace being BGDs' primary facilitation activity: BGDs provided terrace residents with the opportunity to participate in the project and have subsidised SWI installed. They mediated between government funding, the technology and the terrace residents, facilitating the deployment of technology by introducing the opportunity (the technology, financing and energy saving) to residents. This involved channelling funds to the benefit of householders (financial facilitation), the support of an existing community (terrace residents) and the creation of rules for the duration of the project such as $20 \%$ householder contribution, the monitoring of energy use and householder involvement in the open home event and external publicity (regulatory facilitation). A second form of facilitation can be observed in the city-wide open home event, in which two households from the terrace participated. The event disseminated knowledge about the demonstration project and the technology to local residents, providing an opportunity to learn first-hand and during construction about the technology and its implementation. The event turned the terrace into a material demonstration, it created a space in which knowledge, learning and experience could be shared between users and non-users and it attempted to create new social networks (between participating homeowners, event volunteers and visitors). A third and final form of facilitation is evident in the range of further events undertaken. Different events targeted different audiences. As a means of facilitation each event is defined by the transfer of knowledge to others: each event provided an opportunity to others to learn about SWI and its deployment.

Figure 5 summarises the case in a visual map. Key intermediary processes are overlaid in coloured ovals above key events and activities. A key to the map is provided in Annex 1. 


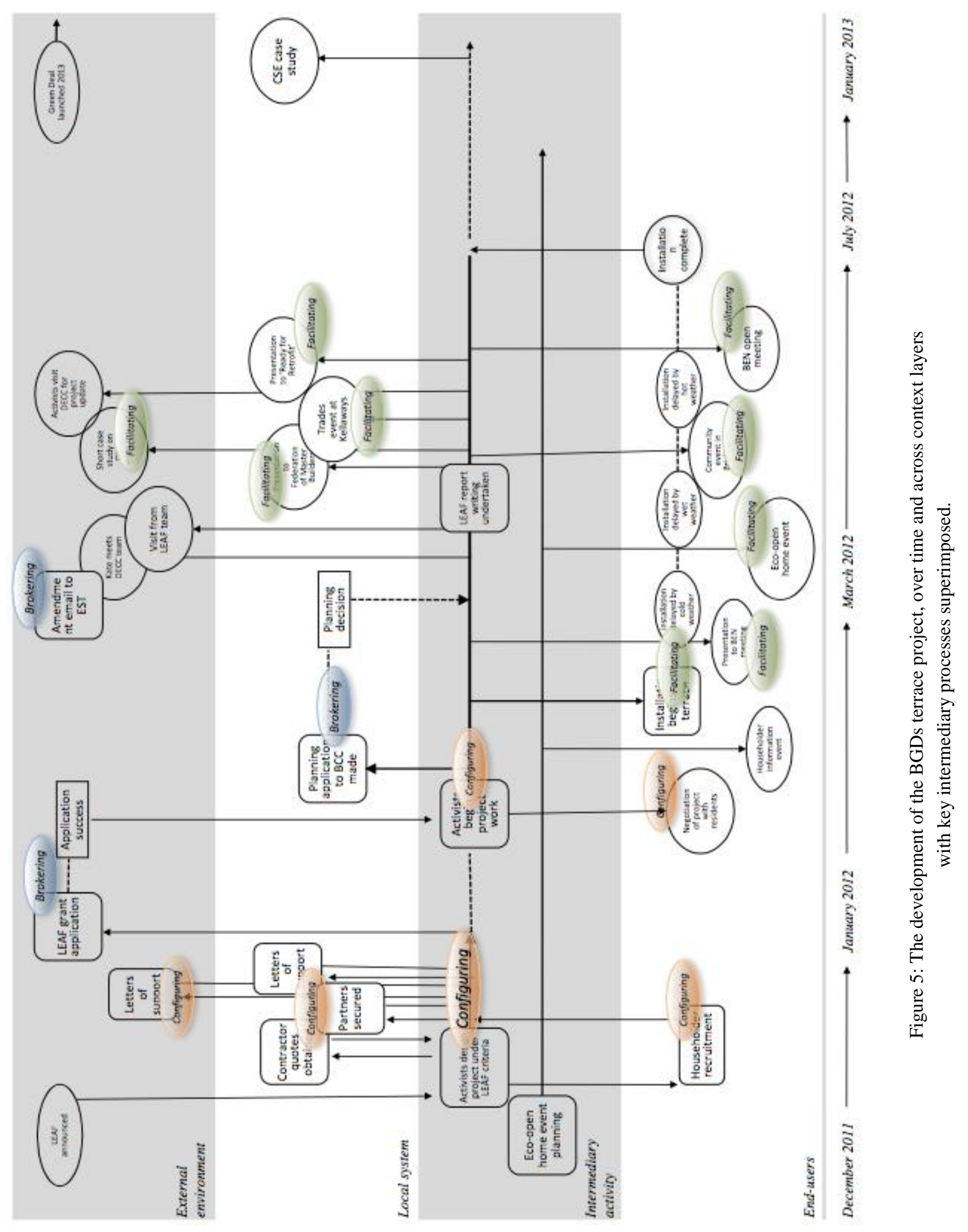




\section{Discussion}

Overall, the case presents a strong fit to the process perspective outlined above. In short, the project was catalysed by the identification of an opportunity. BGDs interpreted national policy, user uptake and local market organisation and used prior experience to configure the project. The primary period of configuring was undertaken in the first two weeks when BGDs made key decisions about the project: the material demonstration at the terrace, its siting and size, who would be involved and how to use it as a material demonstration within the local system (i.e. via events with householders, communities and industry). The primary period of brokering quickly followed in the negotiation of financial resources from DECC without which the project would not have gone ahead. From the successful negotiation of resources, BGDs implemented their project and created a variety of facilitation spaces, including the material installation of the technology, an eco-open homes event and further events with community organisations, trades and the local authority to disseminate knowledge and build momentum behind the technology's use in the local system.

Despite this good fit there are deviations to the basic intermediary sequence that require further examination. Beyond configuring the project within the initial application, further periods of configuring and brokering were undertaken in relation to (1) the material installation (windowsill extensions) and (2) planning permission. The exchange with grant funders over weather related delays also indicates further brokering by BGDs. Because this configuring and brokering occurred during the implementation of the project these deviations can be explained as increasingly detailed cycles of configuring and brokering within the overall project development. They do not as such, alter the basic pattern of intermediary processes. Nonetheless, these deviations suggest the sequence is not linear, there can be movement backwards and forwards or a cycling of key intermediary processes. In particular, a cycle can be observed between configuring and brokering activity, moving from broader project design, through negotiation with others to more detailed project negotiation. Moreover, cycling between processes suggests a flexibility of the project and intermediary activity to local context conditions, a flexibility that may have been important to the successful completion of the project.

Thus, one story told through the model is about user-end intermediation processes: how intermediaries identify project opportunities, and then configure and broker the project, technology and actors to facilitate the local embedding of technology. Each of the five steps can be viewed as typical stages to intermediary project development. Each step builds on the former: facilitation spaces, whether material, social or knowledge-based require some degree configuring: decisions have to be made about their purpose and form. Meanwhile, and at the very least, resources must also be brokered in order for the spaces to be realised. The case above, presents one cycle of this sequence but it is possible to conceive and identify multiple embedded intermediary sequences within. For instance, each engagement event can be conceived as following this pattern.

In turn this points to how insufficient or excessive early configuring and broker influence latter processes. The case suggests maintaining flexibility and adaptability throughout project design and implementation is critical to success. Flexibility allows for learning about contexts of action, users and 
stakeholders. It also means new knowledge can be used to adjust or reconfigure the project during implementation. In turn this suggests that multiple feedback loops could also be identified within the basic sequence.

Situating the key sequence to intermediation within a dynamic context reveals the limited agency of intermediaries in locally embedding low carbon technologies. Their actions are both enabled and constrained by dynamics across layers. The external environment primarily acts as a background influence, for example the origin of the grant or the introduction of the Green Deal policy. Such events and dynamics are clearly beyond the control of intermediaries but provide opportunities which can be seized. These broad dynamics are situated by the local system according to local conditions (geography, politics, market conditions etc.). Intermediaries have greater, although still constrained influence over developments at the level of local socio-technical systems. Target users further enable and constrain intermediation in subtle but significant ways. Overall, this suggests intermediaries should be flexibility and adaptable to evolving context dynamics and opportunities. Thus, a second story of the model is about multiple layers creating a dynamic context for local embedding. Each layer evolves in its own way, exerting influence over the opportunities and possibilities for intermediation.

\section{Conclusion}

This paper started by identifying a key societal issue: a variety of low carbon technologies currently exist that could, if deployed throughout society, make a substantial contribution to reducing the carbon intensity of existing lifestyles. Realising this potential, it was argued, is not simply a question of diffusion but rather of learning about how low carbon technologies get taken up and integrated into increasingly sustainable place-specific socio-technical configurations. This topic was introduced as the process of local embedding, a term increasingly used by scholars but in diverse ways. Accordingly, this paper set out to explore and substantiate the term local embedding through a focus on the role and agency of intermediary organisations.

Although frequently used by transition scholars the term local embedding has not been scrutinised nor developed up until this point. Addressing this topic through the lens of intermediary actors it was argued that common across research on innovation intermediaries and socio-technical transitions is a focus on early stages of innovation processes. For transitions research specifically, this has meant focussing on the work intermediaries do in the 'exploration' and 'take-off' phases (c.f. embedding and stabilisation phases). At the same time, a focus on the key processes and functions of intermediaries has, within these fields, been dominant, whilst less attention has been paid to understanding the context in which they work.

To understand how intermediary actors might contribute to later stages of transitions a process perspective was developed. Insights from three literatures proved useful in this endeavour. Specifically, insights from research on innovation intermediaries provided an understanding of key intermediary processes (what they do) as well as insights into the dynamic context in which they work. Insights from the field of transitions suggested more detailed processes involved in embedding 
technologies (momentum building, aligning system elements, learning-by-doing etc.) and a means to conceive of a structured and dynamic context. Meanwhile, insights from domestication studies brought attention to the use of market-ready technologies and introduced a stronger role for agency in the creation of socio-technical configurations.

The resulting perspective included an ideal-typical sequence to key intermediary processes situated within a dynamic context. A single case study was used to demonstrate the perspective. From it we also learned that deviations exist. This affirms the sequence as semi-linear. It can thus be thought of as ideal-typical or predominant, in the sense it has internal logic and might be expected of an exemplary case. Nonetheless, alternative orderings may also occur as might additional feedback loops between processes. To further qualify and extend the model more case study work is necessary. Situating the sequence within a dynamic understanding of context has also moved beyond mainly decontextualized accounts of key intermediary processes and extended an alternative approach to thinking about space and scale in transition processes.

More broadly, insights from socio-technical transitions research and domestication studies have also proved valuable in enriching and substantiating the process of local embedding. At a course-grained level local embedding concerns how technologies get taken up, adapted and used at a scale above the appropriation of technology by households but below the social of embedding of technology in wider society. More specifically, it concerns the alignment of multiple system elements within emerging place-specific socio-technical configurations. In this sense, local embedding thus builds upon both perspectives foundational notion of the co-construction of technology and society, in which a variety of actors can influence the process (including the neglected role of intermediary actors). In focussing on the role and agency of intermediaries in local embedding the paper has foregrounded key intermediary processes over local embedding processes. As a result, future research could inquire into and refine key local embedding processes (momentum building, alignment etc.) or it could explore socio-spatial conditions that enable specific locations (cities or regions) to build momentum behind particular, low carbon socio-technical configurations. Either way, a focus on local embedding extends attention within transitions research downstream, away from the development of the new, to utilisation of existing low carbon solutions.

\section{Acknowledgements}

This research was made possible through financial support from the Economic and Social Research Council (ESRC) and the University of Sussex. Particular thanks to Adrian Smith and Florian Kern for providing invaluable feedback as well as Paula Kivimaa and participants of the 4S/EASST conference in Barcelona (2016), the SPRU 50 ${ }^{\text {th }}$ anniversary conference (2016). Earlier versions of the paper were also presented at the TRIPOD project workshop (March 2016) and International conference of sustainability transitions in Brighton, September 2015. The comments and suggestions of two anonymous referees have also been very useful. 


\section{References}

Backhaus, J., 2010. Intermediaries as Innovating Actors in the Transition to a Sustainable Energy System. Cent. Eur. J. Public Policy 4, 86-108.

Banks, N., White, V., 2012. Evaluation of solid wall insulation in fuel poor households in the private sector Final Report to eaga Charitable Trust. Bristol, UK.

Berker, T., 2011. Domesticating Spaces: Sociotechnical Studies and the Built Environment. Sp. Cult. 14, 259-268. doi:10.1177/1206331211412259

Bessant, J., Rush, H., 1995. Building Bridges for innovation: the role of consultants in technology transfer. Res. Policy 97-114.

Billig, M., 2013. Learn to write badly. Cambridge University Press, Cambridge, UK.

Boardman, B., 2008. Home truths: A low carbon strategy to reduce UK housing emissions by $80 \%$ by 2050, Report written for the Co-operative Bank and Friends of the Earth

CCC, 2014. Meeting Carbon Budgets - 2014 Progress Report to Parliament. Committee on Climate Change, London, UK

CCC, 2012. How local authorities can reduce emissions and manage climate risk. Committee on Climate Change, London, UK

CCC, 2008. Building a low-carbon economy - the UK's contribution to tackling climate change. Committee on Climate Change, London, UK

Coenen, L., Benneworth, P., Truffer, B., 2012. Toward a spatial perspective on sustainability transitions. Res. Policy 41, 968-979. doi:10.1016/j.respol.2012.02.014

DECC, 2013. Energy Efficiency Strategy 2013. Department of Energy and Climate Change, London, UK.

DECC, 2012. The Energy Efficiency Strategy: The Energy Efficiency Opportunity in the UK. Department of Energy and Climate Change, London, UK.

Elzen, B., van Mierlo, B., Leeuwis, C., 2012. Anchoring of innovations: Assessing Dutch efforts to harvest energy from glasshouses. Environ. Innov. Soc. Transitions 5, 1-18. doi:10.1016/j.eist.2012.10.006

Farla, J., Markard, J., Raven, R., Coenen, L., 2012. Sustainability transitions in the making: A closer look at actors, strategies and resources. Technol. Forecast. Soc. Change 79, 991-998. doi:10.1016/j.techfore.2012.02.001

Fischer, L.-B., Newig, J., 2016. Importance of Actors and Agency in Sustainability Transitions: A Systematic Exploration of the Literature. Sustainability 8, 476. doi:10.3390/su8050476

Fuenfschilling, L., Truffer, B., 2014. The structuration of socio-technical regimes - Conceptual foundations from institutional theory. Res. Policy 43. doi:10.1016/j.respol.2013.10.010

Geels, F., Deuten, J.J., 2006. Local and global dynamics in technological development: a sociocognitive perspective on knowledge flows and lessons from reinforced concrete. Sci. Public Policy 33, 265-275.

Geels, F., Raven, R., 2006. Non-linearity and Expectations in Niche-Development Trajectories: Ups and Downs in Dutch Biogas (1973-2003). Technol. Anal. Strateg. Manag. 37-41. doi:10.1080/09537320600777143

Geels, F.W., 2005. Technological Transitions and System Innovations. Edward Elgar, Cheltenham, UK

Geels, F.W., 2002. Technological transitions as evolutionary reconfiguration processes: a multi-level perspective and a case-study. Res. Policy 31, 1257-1274. doi:10.1016/S0048-7333(02)00062-8

Geels, F.W., Hekkert, M.P., Jacobsson, S., 2008. The dynamics of sustainable innovation journeys. Technol. Anal. Strateg. Manag. 20, 521-536. doi:10.1080/09537320802292982

Geels, F.W., Kern, F., Fuchs, G., Hinderer, N., Kungl, G., Mylan, J., Neukirch, M., Wassermann, S., 2016. The enactment of socio-technical transition pathways: A reformulated typology and a comparative multi-level analysis of the German and UK low-carbon electricity transitions (1990-2014). Res. Policy 45, 896-913. doi:10.1016/j.respol.2016.01.015 
Haddon, L., 2011. Domestication analysis, objects of study, and the Centrality of Technologies in Everyday Life. Can. J. Commun. 36, 311-323.

Hargreaves, T., Hielscher, S., Seyfang, G., Smith, A., 2013. Grassroots innovations in community energy: The role of intermediaries in niche development. Glob. Environ. Chang. 23, 868-880. doi:10.1016/j.gloenvcha.2013.02.008

Heiskanen, E., Jalas, M., Rinkinen, J., Tainio, P., 2015. The local community as "low-carbon lab": Promises and perils. Environ. Innov. Soc. Transitions 14, 149-164. doi:10.1016/j.eist.2014.08.001

Hekkert, M.P., Negro, S.O., 2009. Functions of innovation systems as a framework to understand sustainable technological change: Empirical evidence for earlier claims. Technol. Forecast. Soc. Change 76, 584-594. doi:10.1016/j.techfore.2008.04.013

Hodson, M., Marvin, S., 2009. Cities mediating technological transitions: understanding visions, intermediation and consequences. Technol. Anal. Strateg. Manag. 21, 515-534. doi:10.1080/09537320902819213

Hoogma, R., Kemp, R., Schot, J., Truffer, B., 2002. Experimenting for Sustainable Transport. Spon Press, London, UK.

Howells, J., 2006. Intermediation and the role of intermediaries in innovation. Res. Policy 35, 715728. doi:10.1016/j.respol.2006.03.005

IEA, 2016. Energy Technology Perspective (full report). International Energy Agency, Paris, France IPCC, 2014. Climate Change 2014: Mitigation of Climate Change, Contribution of Working Group III to the fifth Assessment Report of the Intergovernmental Panel on Climate Change. Cambridge University Press, Cambridge, UK.

IRENA, 2016. Conclusions from IRENA's first Innovation Week, 10-13 May 2016 in Bonn.

Jalas, M., Kuusi, H., Heiskanen, E., 2014. Self-Building Courses of Solar Heat Collectors as Sources of Consumer Empowerment and Local Embedding of Sustainable Energy Technology. Sci. Technol. Stud. 27, 76-96.

Kemp, R., Schot, J., Hoogma, R., 1998. Regime shifts to sustainability through processes of niche formation: the approach of strategic niche management. Technol. Anal. Strateg. Manag. 10, 3741.

Kivimaa, P., 2014. Government-affiliated intermediary organisations as actors in system-level transitions. Res. Policy 43, 1370-1380. doi:10.1016/j.respol.2014.02.007

Kivimaa, P., Boon, W., Hyysalo, S., Klerkx, L., 2016. From a systematic review to a dynamic typology of intermediaries in transitions 7-9.

Lægran, A.S., 2005. Escape Vehicles? The internet and the automobile in a local-global intersection, in: Oudshoorn, N., Pinch, T. (Eds.), How Users Matter. MIT Press, Cambridge, Massachusetts, pp. 81-100.

Lamvik, G.M., 1996. Fairy Tale on Wheels: The Car as a Vehicle for Meaning within a Norwegian Subculture, in: Making Technologies Our Own? Domesticating Technology into Everday Life. Scandinavian University Press, Oslo, Norway.

Langley, A., 1999. Strategies for Theorizing from Process Data. Acad. Manag. Rev. 24, 691-710. doi: $10.2307 / 259349$

Lente, H. Van, Hekkert, M., Smits, R., Waveren, B.A.S. Van, 2003. Roles of systemic intermediaries in transition processes. Int. J. Innov. Manag. 7, 247-279.

Lie, M., Sorenson, K.H., 1996. Making Technologies our own? Domesticating Technology into Everyday Life. Scandinavian University Press, Oslo, Norway.

Mallaburn, P.S., Eyre, N., 2013. Lessons from energy efficiency policy and programmes in the UK from 1973 to 2013. Energy Effic. 7, 23-41. doi:10.1007/s12053-013-9197-7

Markard, J., Raven, R., Truffer, B., 2012. Sustainability transitions: An emerging field of research and its prospects. Res. Policy 41, 955-967. doi:10.1016/j.respol.2012.02.013

Moss, T., 2009. Intermediaries and the governance of sociotechnical networks in transition. Environ. 
Plan. A 41, 1480-1495. doi:10.1068/a4116

Nelson, R.R., Winter, S.G., 1982. An Evolutionary Theory of Economic Change. BellKnap Press, Cambridge, Massachusetts.

Pentland, B.T., 1999. Building Process Theory with Narrative: From Description to Explanation. Acad. Manag. Rev. 24, 711. doi:10.2307/259350

Pettigrew, A.M., 1997. What is processual analysis? Scand. J. Manag. 13, 337-348.

Raven, R.P.J.M., Heiskanen, E., Lovio, R., Hodson, M., Brohmann, B., 2008. The Contribution of Local Experiments and Negotiation Processes to Field-Level Learning in Emerging (Niche) Technologies: Meta-Analysis of 27 New Energy Projects in Europe. Bull. Sci. Technol. Soc. 28, 464-477. doi:10.1177/0270467608317523

Rohracher, H., 2005. From Passive Consumer to Active Participants: the diverse roles of users in innovation processes, in: Rohracher, H. (Ed.), User Involvement in Innovation Processes: Strategies and Limitations from a Socio-Technical Perspective. Profil, Munchen, Wein.

Schot, J., Geels, F.W., 2008. Strategic niche management and sustainable innovation journeys: theory, findings, research agenda, and policy. Technol. Anal. Strateg. Manag. 20, 537-554. doi:10.1080/09537320802292651

Schot, J., Kanger, L., Verbong, G., 2016. The roles of users in shaping transitions to new energy systems. Nat. Energy 1, 16054. doi:10.1038/nenergy.2016.54

Schreuer, A., Ornetzeder, M., Rohracher, H., 2010. Negotiating the local embedding of sociotechnical experiments: a case study in fuel cell technology. Technol. Anal. Strateg. Manag. 22, 729-743. doi:10.1080/09537325.2010.496286

Shove, E., Walker, G., 2007. CAUTION! Transitions ahead: politics, practice and sustainable transition management 1-10. Environ. Plan. A 39, 4 763-770 doi:10.1068/a39310

Silverstone, R., Hirsch, E., Morley, D., 1992. Information and communication technologies and the moral economy of the household, in: Silverstone, R., Hirch, E. (Eds.), Consuming Technologies: Media and Information in Domestic Spaces. Routledge, London, pp. 15-31.

Smith, A., 2007. Translating Sustainabilities between Green Niches and Socio-Technical Regimes. Technol. Anal. Strateg. Manag. 19, 427-450. doi:10.1080/09537320701403334

Smith, A., Raven, R., 2012. What is protective space? Reconsidering niches in transitions to sustainability. Res. Policy 41, 1025-1036. doi:10.1016/j.respol.2011.12.012

Smith, A., Stirling, A., Berkhout, F., 2005. The governance of sustainable socio-technical transitions. Res. Policy 34, 1491-1510. doi:10.1016/j.respol.2005.07.005

Smith, A., Voß, J., Grin, J., 2010. Innovation studies and sustainability transitions: The allure of the multi-level perspective and its challenges. Res. Policy 39, 435-448.

doi:10.1016/j.respol.2010.01.023

Sorenson, K., 1996. Learning technology, constructing culture, STS Working paper 18/1996. Trondheim, Norway

Sorenson, K.H., Aune, M., Halting, M., 2000. Against Linearity: On the Cultural Appropriation of Science and Technology, in: Dierkes, M., von Grote, C. (Eds.), Between Understanding and Trust: The Public, Science and Technology. Routledge, London, UK, pp. 237-257.

Späth, P., Rohracher, H., 2012. Local Demonstrations for Global Transitions-Dynamics across Governance Levels Fostering Socio-Technical Regime Change Towards Sustainability. Eur. Plan. Stud. 20, 461-479. doi:10.1080/09654313.2012.651800

Steward, F., 2012. Transformative innovation policy to meet the challenge of climate change: sociotechnical networks aligned with consumption and end-use as new transition arenas for a low-carbon society or green economy. Technol. Anal. Strateg. Manag. 24, 331-343.

Stewart, J., 2007. Local Experts in the Domestication of Information and Communication Technologies. Information, Commun. Soc. 10, 547-569. doi:10.1080/13691180701560093

Stewart, J., Hyysalo, S., 2008. Intermediaries, Users and Social Learning in Technological Innovation. Int. J. Innov. Manag. 12, 295-325. doi:10.1142/S1363919608002035 


\section{Annex 1: guide to visual map}

The visual map can be read as a brief overview of the main events, installations and activities within the case study. It is a visual depiction of the complete case study within a single page. The visual map is composed of:

1. Boxes - the boxes contain brief description of the main elements of the case chronology relevant to the local embedding. Oval boxes represent events carried out by the focal intermediary. Circles represent material installations of the focal technology. Round-cornered rectangles present activities carried out by the focal intermediary. Square-corned rectangles present events and decisions outside the control of the intermediary.

2. Four horizontal bands - Each event, installation and activity can be classified as occurring in relation to a place-specific context represented by the four different horizontal bands on the flow chart. The lower central band to which all boxes are connected contains activity of the intermediary. The other bands situate events, installations and activities according to the context in which they are performed. Boxes that cut across more than one band are used to indicate events, installations or activities that can be associated with two or more domains.

3. Arrows - Vertical arrows leading from one domain to another indicate direct influences from events, installations and activities on subsequent events, installations or activities. Horizontal arrows within bands are used to indicate continuity of event or activity over time. Continuous arrows show strong and stable activity over time. Dotted horizontal arrows show disruption and disturbance within the activity. Curved dotted arrows are used to indicate indirect influences on events, installations and activities.

6. Time scales - the time scales along the bottom is distorted in order to keep the size of the charts to a minimum whilst including periods of high velocity events.

7. Key intermediary processes - finally key intermediary processes of facilitating, configuring and brokering are superimposed over the events, installations and activities corresponding to identified activities. 


\section{Recent papers in the SPRU Working Paper Series:}

July

Who Gains from High-Tech Growth? High-Technology Multipliers, Employment and Wages in Britain. Neil Lee and Stephen Clarke

June

Measures, Drivers and Effects of Green Employment: Evidence from US Local Labor Markets, 2006-2014. Francesco Vona, Giovanni Marin and Davide Consoli

Structural Changes and Growth Regimes. Tommaso Ciarli, André Lorentz, Marco Valente and Maria Savona

Explaining Sociotechnical Transitions: A Critical Realist Perspective. Steve Sorrell

Social Innovation, Democracy and Makerspaces. Adrian Smith

Adoption and Diffusion of Micro-Grids in Italy. An Analysis of Regional Factors Using Agent-Based Modelling. Francesco Pasimeni

\section{May}

The Measurement of Synergy in Innovation Systems: Redundancy Generation in a Triple Helix of University-Industry-Government Relations. Loet Leydesdorff, Henry Etzkowitz, Inga Ivanova and Martin Meyer

\section{March}

Inclusive Innovation and Rapid Sociotechnical Transitions: The Case of Mobile Money in Kenya. Elsie Onsongo and Johan Schot

Does Managerial Experience Affect Strategic Change? Matte Hartog and Frank Neffke Coworker Complementarity. Frank Neffke

\section{February}

Technical Skills, Disinterest and Non-Functional Regulation: Energy Efficiency Barriers Viewed in an Ecosystem of Energy Service Companies. Hanna-Liisa Kangas, David Lazarevic and Paula Kivimaa

\section{Suggested citation:}

Jake Barnes (2017). User-Intermediaries and the Local Embedding of Low Carbon Technologies. SPRU Working Paper Series (SWPS), 2017-15: 1-23. ISSN 2057-6668. Available at: www.sussex.ac.uk/spru/swps2017-15

\section{SPRU - Science Policy Research Unit}

University of Sussex

Falmer, Brighton, BN1 9SL,United Kingdom

SWPS Website: www.sussex.ac.uk/spru/research/swps

SPRU Website: www.sussex.ac.uk/spru

SPRU Twitter: @SPRU 